"Consumer attitudes towards sponsors of the South African national rugby team"

Catherine Mpolokeng Sephapo
Cindy Erdis

Catherine Mpolokeng Sephapo and Cindy Erdis (2016). Consumer attitudes

ARTICLE INFO towards sponsors of the South African national rugby team. Problems and

Perspectives in Management, 14(3-3), 617-626. doi:10.21511/ppm.14(3-

3). 2016.04

DOI

http://dx.doi.org/10.21511/ppm.14(3-3).2016.04

RELEASED ON

Thursday, 10 November 2016

JOURNAL

"Problems and Perspectives in Management"

FOUNDER

LLC "Consulting Publishing Company "Business Perspectives"

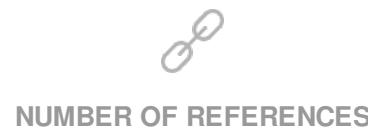

0

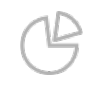

NUMBER OF FIGURES

0

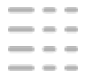

NUMBER OF TABLES

0

(C) The author(s) 2023. This publication is an open access article. 


\title{
Consumer attitudes towards sponsors of the South African national rugby team
}

\begin{abstract}
The primary objective of the study is to explore the attitudes that consumers in Tshwane have towards the sponsors of the South African National Rugby team, commonly known as the Springboks as a result of the sponsorship partnership. Qualitative data collected by means of focus groups and naïve sketches were analyzed through content analysis. The study found that participants had a positive attitude towards the sponsors of the Springboks. This positive attitude was because participants felt that sponsors were endorsing good values that they perceived to be important, such as teamwork, healthy living and nation building.
\end{abstract}

Keywords: consumers, attitudes, sponsorship, rugby, Springboks.

JEL Classification: M30.

\section{Introduction to sponsorship}

The global economic recession in recent years has impacted on sports sponsorship, however, since 2013, the South African sponsorship industry has reported growth despite the recession (Nevilll, 2014). South Africa's sports sponsorship investment was worth R7.5 billion in 2013 and this figure was inclusive of direct sponsorship of teams, events, broadcast rights, as well as leveraging tools (Nevilll, 2014). Sports are seen as a vehicle by many companies, as it is enjoyed by the diverse South African nation. According to research conducted by Repucom (2012), the top three sporting activities that South Africans display interest in are soccer, rugby and cricket. It could possibly be for this reason that these sports attract massive sponsorship deals from multimillion rand entities in the South African economic system.

The South African Football Association (SAFA) broadcasted the R25 million sponsorship deal with Burger King in September 2015 (Kickoff, 2015). This deal was believed to extend over five years and will drive the U19 Inter-Provincial tournament and the U20 Men's National Team, Amajita (Kickoff, 2015). Cricket is also a sport that has seen large sponsorship revenue generated for the organization. Cricket South Africa's four-year sponsorship agreement with Standard Bank was worth \$19 million (Pedroncelli, 2016). The sponsorship agreement in place allowed for Standard Bank's logo to be printed on the national team's shirts in all three formats of the modern cricket game (Pedroncelli, 2016). Companies such as Standard Bank do not extend their involvement in South African sport to cricket, but were also affiliated with soccer. The South African bank has been involved in soccer

(C) Catherine Mpolokeng Sephapo, Cindy Erdis, 2016.

Catherine Mpolokeng Sephapo, Lecturer in Marketing Management, Department of Marketing and Retail Management, University of South Africa, South Africa.

Cindy Erdis, Senior Lecturer in Marketing Management, Department of Marketing and Retail Management, University of South Africa, South Africa. sponsorship for many years, with the Africa Cup of Nations (AFCON) tournament seeing Standard Bank as the official financial services provider for some time (Pedroncelli, 2016).

Rugby is also considered to receive the lion's share of sponsorship. The sale of TV rights has long been the life blood of the sport; however, lately rugby has placed itself in such a way that the revenue made from sponsorship forms the largest source of revenue (Carmel, 2015). Absa's sponsorship of the South African National rugby team; commonly known as the Springbok team; contributed enormously to revenue with an estimated worth of R50 million annually. This sponsorship deal was in place from July 2011 to December 2015. BMW also became a sponsor of the Springboks (Sport24, 2015). This sponsorship deal was projected to be valued at R40 million over five years (Styan, 2012). However, the sponsorship of the Springboks agreement between Absa and BMW came to an end in 2015 when the respective companies decided not to renew their sponsorships (Sport24, 2015).

As can be seen from the above discussion, the 'most' popular sports in South Africa attract competitive sponsorship deals, however, what is seen as 'smaller' sports also attract significant sponsorship deals. Netball for example was a custodian a sponsorship from one of South Africa's supermarkets; Spar; Which ran from January 2013 to December 2015 and was worth R20 million (News 24; 2013).

According to Nevill (2014), the South African sports sponsorship industry can be viewed as "healthy", as sponsorships are delivering on their strategic objectives. With organizations spending so much of their marketing budgets, the objective this study aims to explore is the attitudes that consumers in Tshwane have towards the sponsors of the South African National Rugby team, commonly known as the Springboks as a result of the sponsorship partnership. The secondary objectives of the study are discussed below and a literature review on 
consumer attitudes follows. The findings of the study, as well as the recommendations and conclusions are presented last.

\section{Objectives of the study}

The main objective of the study is to explore the attitudes that consumers in Tshwane have towards the sponsors of the South African National Rugby team, commonly known as the Springboks as a result of the sponsorship partnership. The secondary objectives of the study are as follows:

- To explore the extent to which consumers display interest in ruby.

- To explore the extent to which consumers understand the premise of sponsorship.

The next section will provide an overview of the South African National Rugby team, as well as theoretical studies on the influence of attitudes on consumer behavior.

\section{Literature review}

Sponsorship means the scrutinizing, development, execution and administration of all actions that are linked to businesses or establishments' providing cash, material, amenities or knowledge for the advertising of individuals and/or organizations with the arrangement of the sponsor's service and the sponsored party's consideration in order to achieve the objectives of marketing and corporate communication at the same time (Dos Santos, 2014, p. 240). According to Ferrand, Torrigiani and Povill (2007, p. 47), sponsorship can be seen as a communication approach that is cohesive within the set of strategies used by an entity with the aim of achieving both marketing and business goals, exploiting the rights to associate an entity, brand, a product with another entity, an event or a celebrity, involving a commercial transaction between the parties.

Bühler \& Nufer (2010, p. 90) mentions that sponsorship can take various forms which include cultural, education, social, environmental, sporting organization sponsorship or individual sponsorship deals. Sponsorship may be for sporting organizations or individuals, including individual athletes, clubs and teams, events, sporting leagues, unions, competitions, venues and special causes (Smith, Graetz \& Westerbeek, 2008, p. 192). The definition that will be adopted in this this study is that of Alay (2008, p. 8) where the author defines sponsorship as the provision of resources (money, people and equipment) by an organization (the sponsor) directly to an individual, authority or body (the sponsored entity), to enable the latter to pursue some activity in return for benefits contemplated in terms of the sponsor's promotion strategy which can be expressed in terms of corporate, marketing or media objectives.
The discussion thus far has demonstrated the value that organizations place on sponsorship by spending large portions of their marketing budgets in order to achieve specific objectives. The success of any marketing communication tool needs to be measured, however, due to the amount of money organizations invest in sponsorship, critics may be apprehensive about the capability to quantity the true effectiveness of sponsorship (Du Plessis, Van Heerden \& Cook, 2010, p. 297). Table 1 illustrates the effects can or should be measured to ensure that the sponsor has achieved a significant return on sponsorship investment. Table 1 serves to indicate the type of effect that sponsors may seek to achieve through the sponsorship - examples or applications of effectiveness are offered for each effect.

Table 1. Type of effect specified in sponsorship objectives

\begin{tabular}{|l|l|}
\hline \multicolumn{1}{|c|}{ Type of effect } & \multicolumn{1}{c|}{ Results - example or application of effectiveness } \\
\hline Brand & Increased fondness for the sponsor's brand \\
\hline Sales & Increased sales \\
\hline Stimuli & Arousal, involvement and pleasure \\
\hline Recall & $\begin{array}{l}\text { Among others, increased recall of sponsor's name, logo and } \\
\text { slogan }\end{array}$ \\
\hline Image & Enhanced corporate image \\
\hline Positioning & Position new sponsor's involvement \\
\hline Media & Quantity and quality of publicity generated \\
\hline Awareness & Increased sponsorship awareness \\
\hline Relationship & $\begin{array}{l}\text { Increase in relationship building among selected } \\
\text { stakeholders }\end{array}$ \\
\hline Association & $\begin{array}{l}\text { Associate sponsor with friendliness, goodness or closeness } \\
\text { to community }\end{array}$ \\
\hline Attitude & Attitude towards sponsor \\
\hline Recognition & Familiarity tracking \\
\hline
\end{tabular}

Source: Du Plessis et al. (2010, p. 298).

The primary objective of the study is to explore the attitudes that consumers in Tshwane have towards the sponsors of the South African National Rugby team, commonly known as the Springboks as a result of the sponsorship partnership. Companies spend millions to be associated with the Springboks, therefore, it would be imperative to determine whether this sponsorship is achieving an effect on consumer attitudes. The discussion will now provide an overview on the South African national rugby team and, then, elaborate on how consumers develop attitudes. The literature review is concluded by a discussion of the impact of consumer attitudes on the behavior of consumers.

\subsection{The South African national rugby team (The} Springboks). South Africa participated in their very first international rugby competition in 1891, but it was not until they toured Britain in 1906 that they became known as the Springboks with the springbok as the official symbol (Telegraph Media, 2008). In 1977, the Gleneagles Agreement was signed by the members of the Commonwealth which discouraged 
any sporting contact with South Africa as a result of the apartheid policy (Rugby Football History, 2007). However, from 1990 to 1991, the legal apparatus of apartheid was abolished and the Springboks were allowed to compete in international rugby competitions (Springbok Supporter, 2011). The Springboks are a team that brings about national pride and participate in various international competitions such as the Rugby World Cup, as well as the Rugby Championship. The Springboks have become a world renowned brand that organizations want to be associated with. It can be for this reason that various types of sponsors for the Springboks can be identified.

2.2. Consumer attitudes. According to the model of consumer behavior, attitudes are considered to be an internal factor that influences consumer behavior. Research by Kim, Ko and James (2011, p. 569) has highlighted the importance of measuring attitudes towards sponsors as an important indicator of sponsorship effect. An attitude can be defined as a learned tendency to carry oneself in a reliably positive or adverse way towards a particular object or idea (Kardes, Cline \& Cronley, 2011, p. 246). Attitudes towards brands are customers' learned propensities to assess brands in a constructive or adverse way ( $\mathrm{Du}$ Plessis et al., 2007, p. 194). This construct can be captured through three components, namely, the cognitive component, the affective component and the behavioral component.

Attitude is identified as a factor that influences how consumers will react to marketing stimuli and how they will react to a product. Marketers seeking sponsorship opportunities or considering using sponsorship as a marketing communication tool should be aware of how consumers develop their attitudes. Figure 1 illustrates the model of attitude formation as suggested by Shank (2009, p. 123).

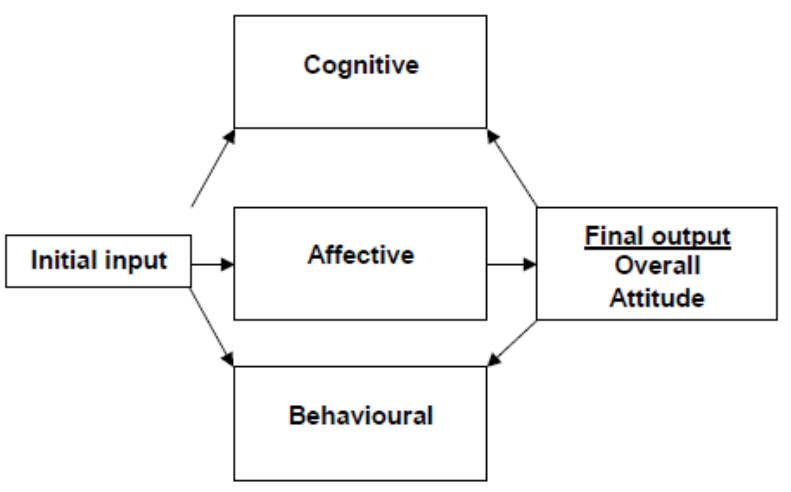

Fig. 1. Model of attitude formation

Source: adapted from Shank (2009, p. 123).

As can be seen from Figure 1, the initial input is required to begin the process. This initial input could be the specific given object the attitude is directed towards. Where this study is concerned, the initial input that consumers consider could be the sponsoring companies themselves or the sponsorship agreement between the sponsors and the sponsored organizations. The model of attitude formation suggests that an attitude is based on the consumer's thinking, feelings and actions towards the initial input or the given object (Shank, 2009, p. 123). The cognitive component refers to the knowledge and perceptions that are acquired by direct experiences and linked information from a variety of sources. This knowledge takes the form of beliefs. Beliefs may not entirely be true; however, they are what consumers perceive to be true about the initial input (Cant, van Heerden \& Ngambi, 2010, p. 58). If the cognitive thoughts or beliefs are prominent in the consumers' memory, the impact will be greater on the consumers' attitudes and, thus, their behavior (Mason, 2005, p. 32). The affective component of attitude is based on feelings or emotional reactions to the initial input (Shank, 2009, p. 123). This simply means that consumers associate how they feel regarding the initial input as their attitude towards the initial input. The last component in the model of attitude formation is the behavioral component. This component is concerned with the probability or inclination of a consumer acting in a meticulous way towards the initial input. It may express the consumers' intentions to act in a positive manner in response to the initial input (Du Plessis et al., 2007, p. 197).

Consumers, ultimately, desire all three attitude components to be melodious, therefore, changing their general attitudes. A corporate sponsor becomes optimistic that the consumers' positive outlooks regarding the sponsored team or organization will become allied with their corporation. It is, therefore, important that attitudes of consumers be understood when strategic decisions are made, since they influence the end behavior of consumers.

\subsubsection{Impact of attitudes on consumer behavior.} Carvalho (N.D) highlights a view that a positive attitude towards an organization or brand influences behavior is seen as a controversial notion. Pride and Ferrel (1991) in Carvalho (N.D) trust that consumer attitudes towards an organization and its products significantly impact the victory or failure of the organization's advertising plan. Solomon (2004), in Carvalho (N.D), states that there is no confirmation that such a correlation can be established or not. Carvalho (N.D) declares that the effect of a consumer's attitude on the way they will behave depends on a number of variables such as level of participation, understanding and experience, accessibility of attitudes, situational variables, as well as personality variables Carvalho (N.D).

When organizations make use of marketing communication tools such as sponsorship, the sponsor expects the customer's optimistic outlooks for the sponsored organization or event will become 
interrelated with their organization (Mason, 2005, p. 34). Once these feelings become linked, what is known as a "halo effect" may then advocate to customers that the sponsor's products are better than those offered by competing organizations (Mason, 2005 , p. 34). Consequently this feeling of "good corporate citizen" for sponsoring the organization or event may make customers accept that the sponsor makes superior products (Mason, 2005, p. 34).

Jalleh, Donovan, Giles-Corti and Holman (2002, p. 38) describe various ways in which attitude effects of sponsorship may occur:

- Pure exposure may translate into outlooks of awareness and ease, henceforth optimistic outlooks toward the message projected by the organization. In this manner, sponsorship may emphasize a perception of the social norm or social acceptance of a message. Additionally, awareness enables other advertising initiatives by informing consumers.

- Because attitudes are founded on various beliefs, an expressed attitude toward an entity, brand name, or health message is reliant upon the beliefs most prominent at the time. Hence, because sponsorship can increase the salience of a belief, sponsorship can influence attitude.

\section{Methodology of the study}

The primary objective of the study was to explore the attitudes that consumers in Tshwane have towards the sponsors of the South African National Rugby team, commonly known as the Springboks as a result of the sponsorship partnership. The study made use of a qualitative approach, as it would provide the researcher with great insight, as well as rich data regarding the attitudes consumers have towards the sponsors of the Springboks. Qualitative research allows the researcher to observe consumers' reactions and hear consumers discuss marketing topics under investigation in the manner in which they understand them. A non-probability snowball sampling method was used to collect primary data. Non-probability was deemed suitable for the study, as it allowed the researcher to arbitrarily select which elements to include in the sample (Malhotra, Birks \& Wills, 2012, p. 501). Snowball sampling was deemed suitable as the study targeted individuals who possessed the required characteristics of the target population (Malhotra, Birks \& Wills, 2012, p. 501). The researcher relied on the researcher's judgement to identify the initial individuals who conformed to the inclusion criteria. The inclusion criterion was inclusive of:

- any male and female individuals 18 years or older;

- any individual who had been exposed to a Springbok rugby match (discussed more in the section that follows);

- any individual who lived in the Tshwane area within Gauteng;

- any person, who was able to comprehend, recite, transcribe and express themselves in English.

Individuals who have been exposed to a Springbok match were included in the sample for the study. The term 'exposed' in the framework of the study was delineated as to include individuals:

- that have viewed a Springbok match at any rugby stadium or on a television set;

- that has seen branding on the Springbok playing kit;

- that have seen sponsor messages on a television set or at any rugby stadium;

- that attended a Springbok match as a social activity and in the process was exposed to sponsor messages and branding.

Two focus groups consisting of six participants in each focus group were used to gather primary data from the sample drawn. All participants of the focus groups were also required to complete naïve sketches before the focus groups commenced. The questions in the naïve sketches were, then, asked in the focus groups whereby participants were encouraged to express their true feelings about their attitudes towards the sponsors of the Springboks. After two focus groups, no new data was obtained which indicated data saturation. According to Nixon and Wild (2010), data saturation can be regarded as the point at which no additional data is found.

Focus group transcripts, as well as twelve (12) completed naïve sketches were analyzed by means of content analyzes. The steps in the content analysis process highlighted by Zhang and Wildemuth (n.d., pp. 2-5) were undertaken in the analysis process.

The limitations of the study will be discussed in the following section.

3.1. Limitations of the study. The limitations applicable to this study are the following:

- The sampling technique utilized in this study was the snowball sampling technique. It was for this reason that not all consumers within the Tshwane area were included in the sample.

- The nature of the study at hand was exploratory in nature and, therefore, the findings cannot be generalized to the population at large. The purpose of the study was to explore the attitudes that consumers in Tshwane have towards the sponsors of the South African National Rugby team, commonly known as the Springboks as a result of the sponsorship partnership. 


\section{Results}

The summary of the demographic profile of participants, as well as the findings to follow in the next section will, therefore, be based on the data collected in the two focus groups, as well as a total of twelve (12) naïve sketches completed by participants in the focus groups.

4.1. Demographic profile of participants. The participants of the study were identified based on the inclusion criteria explained in the methodology section of the study. The participants of the study consisted of $83 \%$ females (10 individuals) and $17 \%$ males (2 individuals). This was due to the availability of the participants during the data collection period. An equal number of male and female participants were invited to participate in the study, but only $17 \%$ of the invited males could attend. The researcher, therefore, commenced with the data collection.

Table 2 illustrates the age distribution of the participants of the study. As can be seen from Table 2, $42 \%$ of the participants (5 individuals) were between the ages of 18 and 25 years. The majority $(58 \%)$ of the participants were between 26 and 35 years, representing 7 of the 12 participants.

Table 2. Age distribution of participants in the study

\begin{tabular}{|c|c|c|}
\hline Age & Number of participants & Percentage \\
\hline $18-25$ years & 5 & $42 \%$ \\
\hline $26-35$ & 7 & $58 \%$ \\
\hline TOTAL & 12 & $100 \%$ \\
\hline
\end{tabular}

The next demographic component that will be discussed is that of the racial distribution of the participants in the study. In the study, 25\% (3 individuals) of the participants were black, 33\% (4 individuals) were white and $25 \%$ ( 3 individuals) were Indian, $8 \%$ (1 individual) were coloured and $8 \%$ (1 individual) were Asian. The race profile of participants was particularly important, as rugby appeals to a wide range of cultural groups.

The research findings from the focus groups and the naïve sketches will now be discussed.

4.2. Findings from the focus groups and naïve sketches. The raw data from the focus group transcripts and naïve sketches were analyzed by means of content analysis. As a result, themes and categories were generated in order to make sense of the data obtained. The discussion of the findings of the study will be presented according to the themes and categories illustrated in Table 3.

Table 3. Themes and categories generated from the study

\begin{tabular}{|c|c|c|}
\hline Themes & Categories & Objectives \\
\hline $\begin{array}{l}\text { Theme 1: Interest } \\
\text { displayed in rugby }\end{array}$ & $\begin{array}{ll}\text { 1. } & \text { Interested } \\
\text { 2. } & \text { Neutral } \\
\text { 3. } & \text { Negative }\end{array}$ & $\begin{array}{l}\text { Secondary objective 1: To } \\
\text { explore the extent to } \\
\text { which consumers display } \\
\text { interest in ruby }\end{array}$ \\
\hline
\end{tabular}

\begin{tabular}{|c|c|c|c|}
\hline $\begin{array}{l}\text { Theme 2: Definition } \\
\text { of sponsorship }\end{array}$ & $\begin{array}{l}1 . \\
2 .\end{array}$ & $\begin{array}{l}\text { Providing } \\
\text { resources } \\
\text { Social } \\
\text { responsibility }\end{array}$ & $\begin{array}{l}\text { Secondary objective } 2 \text { : To } \\
\text { explore the extent to } \\
\text { which consumers } \\
\text { understand the premise of } \\
\text { sponsorship }\end{array}$ \\
\hline $\begin{array}{l}\text { Theme 3: Attitude } \\
\text { towards the } \\
\text { sponsors of the } \\
\text { Springboks }\end{array}$ & 1. & $\begin{array}{l}\text { Positive attitude } \\
\text { towards the } \\
\text { sponsors }\end{array}$ & $\begin{array}{l}\text { Primary objective: to } \\
\text { explore the attitudes that } \\
\text { consumers in Tshwane } \\
\text { have towards the } \\
\text { sponsors of the South } \\
\text { African National Rugby } \\
\text { team, commonly known } \\
\text { as the Springboks as a } \\
\text { result of the sponsorship } \\
\text { partnership. }\end{array}$ \\
\hline
\end{tabular}

Theme 1: Interest displayed in rugby. Secondary objective 1 of the study aimed to explore the extent to which consumers display interest in ruby. This would provide an indication of participants' involvement in rugby and some of the reasons why consumers go to rugby matches. It was important to determine the extent to which participants were interested in the sport of rugby, because the level of interest may in some way impact the participants' disposition towards marketing tools used in the sport. These participants were qualified to participate in the study, as they had knowledge of rugby and had been exposed to the sport in various contexts, such as on a television set or at a sporting arena. From the findings, three categories can be identified, which are discussed below.

Category 1: Interested. From the focus group interviews and naïve sketches, it was clear that the participants were interested in rugby, though for various reasons. They watched rugby or had been exposed to a Springbok game, because they enjoyed rugby. Some of the participants were interested in rugby because they grew up watching the sport. Although knowledge of the rules and regulations relating to the sport may have been limited, the participants still enjoyed watching rugby. Some of the participants pointed out that they enjoyed watching rugby because rugby brings people of different cultures together and unites the nation. Direct narratives from the naïve sketches, indicating the various reasons why interest was displayed by the participants, are given below:

- "... I watch it to spend time with people who watch it ..."

- "Though I do watch it, my knowledge of the rules and how it's played is limited".

- "I love rugby because it has a combination of white and black cultures and represents the unique sport culture of SA ..."

- “... it is the pride of SA ..."

- “... We grew up with rugby as a sport and therefore still watch it. My spouse is also very passionate about the sport which also increases my interest ..."

- “... it brings various walks of life together with the same goal of supporting a team ..." 
- "... it is a fun game to watch ..."

- "... I enjoy the thrill of the game ..."

- "... Grew up with it ..."

- “... we played rugby at school ..."

In the next category, participants displayed a neutral response to rugby. In this context, neutral means that the participants were not necessarily devoted to rugby, nor did they have a negative perception of the sport.

Category 2: Neutral. Some of the participants included in the sample displayed a neutral response to rugby. In essence, these participants were not necessarily interested in rugby, but neither did they disregard the sport. The reason for the neutral response as indicated by the participants was that the only time these individuals were exposed to the sport was during big events such as the Rugby World Cup. The social aspect also motivated the participants to watch rugby. The participants indicated that they enjoyed watching rugby when they could spend time with their friends and family members. Watching rugby was essentially a platform for them to have a good time with their loved ones in a relaxed and favorable environment. Lastly, some participants indicated that they were not necessarily interested in rugby, but they did follow the general performance of the national team. For example, they were interested in how well the Springboks were doing in the World Cup or how the teams perform in tournaments such as the Currie Cup.

The following narratives were extracted from the focus group interviews and the naïve sketches to validate the findings:

- "Not really. I am not a huge fan of sports in general. The only time that I watch rugby is during the World Cup".

- "I don't mind watching the sport, but this is mainly due to the social aspect involved ..."

- "... watching the game with friends and family makes it more interesting as we have bets between each other ..."

- "... watch during the world cup due to the atmosphere and vibe ..."

- "... I watch when it is showing and I am in the area, will then cheer enthusiastically ..."

- “... I won't go out of my way to watch a game, however, like supporting big matches such as the World Cup ..."

- "it was never one of our favorite sports growing up ..."

- “... We were more into soccer, my dad played soccer".

- 'I don't watch the games as much, but I follow the progress of the team [SA rugby team] ..."

As can be seen from the above findings, the participants indicated that they neither disregarded rugby, nor strongly followed rugby. From the direct quotes it is clear that these individuals would not initiate watching a rugby match themselves, but they did not mind attending a rugby match when suggested by friends, for example. It can also be deduced from the direct quotes that these participants placed value on the social aspect surrounding a rugby match.

Category 3: Negative. In the next category, participants demonstrated negative responses towards rugby, meaning that they did not display any interest in rugby. The participants that were not interested in rugby pointed out that they thought rugby was a very aggressive sport and, therefore, not really to their taste. Although the participants were not interested in rugby per se, they were qualified to participate in the study as they had been exposed to the sport and, subsequently, to marketing messages from sponsors. The following direct quotes were extracted from the focus group interviews in order to validate the findings regarding the negative response to rugby:
- “... it is a very aggressive sport which isn't to my taste ..."
- “... It was never one of my favorite sports growing up ..."

A question one can ask from the findings is why there would be individuals in the target population who held negative responses regarding rugby or those who may not have particularly liked the sport. It is important to note that the sample for this study was drawn from individuals who had been exposed to a Springbok match. The term 'exposed' in this context can be delineated to include various scenarios, as mentioned in section 4. Although these participants did not display much interest in rugby, they could have still been exposed to messages from the sponsor. Consumers may consume rugby for various reasons, one of them being a social activity. The value that participants place on the social activity could outweigh the negative view of the sport and thus result in them attending a Springbok match. The aim of the study was to explore the attitudes that consumers in Tshwane have towards the sponsors of the South African National Rugby team, commonly known as the Springboks as a result of the sponsorship partnership. Therefore, someone may be at a game with no intention to consume marketing messages, but leave with the intention to find out more about a sponsor brand to which they were exposed during a rugby match.

Theme 2 addresses the participants' general understanding of the term sponsorship.

Theme 2: Definition of sponsorship. This question in the naïve sketches describes the participants' understanding of the term 'sponsorship'. The participants were required to define this term in their 
own words. According to Bühler and Nufer (2010, p. 90), sponsorship can take numerous forms which may include cultural, education, social, environmental, sporting organization sponsorship or individual sponsorship deals. Shilbury et al. (2009, p. 247) define sponsorship as the provision of resources (money, people and equipment) by an organization (the sponsor) directly to an individual, an event or entity, which yields some privileges and association, that may be used for commercial advantage. Two categories were identified from the findings denoting the participants' description of what they perceived sponsorship to be and are discussed next.

Category 1: Providing resources. From the findings, it was found that most participants understood the term 'sponsorship' as meaning a form of providing resources/funding (either financial or material) to the team that has multiple benefits. Participants understood that sponsorship as a marketing and communications tool could promote brand awareness for the sponsor and exposure to the product, and enhances the image, as well as the reputation of all parties involved. Sponsorship agreements were, therefore, seen as a mutual process of exchange between parties. The following quotes were taken from the focus groups and the naïve sketches to validate the findings:

- "I think it is mostly organizations, maybe supporting a person or another organization. So either financially or with products but it is usually for their commercial gain. So either financially or with products, but it is usually for their commercial gain".

- "I think it is basically supplying with money or physical iPhones for the purpose of getting your brand recognized and shown somewhere".

- "But again a lot of companies use sponsorship as a way of getting free marketing from these non-profit organizations, as well as these sports clubs and whatever so it is a win-win situation, they get money at the gate, exposure, publicity and stuff like that".

- “... for example, a rugby team and from that they get the benefit of attaching their brand to the team. This earns them an audience of possible customers who support the team".

- "Brand attributing monetary means to a team in exchange for marketing ..."

- “... a paid method or organizations that provides financial support to certain non-profit organizations/clubs in order to gain advertising or exposure or publicity ..."

- “... associated with a sporting event, enhances sponsors image and reputation".

- " "... the sponsor usually has the aim of achieving commercial gain such as exposure and awareness of the organization".
- "Sponsorship is by all means coming from supporting stakeholders, to support the course thereof. It is done by either by offering free goods and/or services ..."

- "A brand paying for marketing space, time and recognition based on the recognition of the team sponsored".

Category 2: Social responsibility. Participants also mentioned that sponsorship can encompass social responsibility. According to Investopedia (2016), corporate social responsibility refers to initiatives that businesses involve themselves in that benefit the community. These initiatives can vary and may improve the organization's image in the minds of community members. Participants of this study highlighted that sponsorship could also form part of a company's corporate social responsibility initiative when working with non-profit organizations. The following quotes were taken from the focus groups and the naïve sketches to validate the findings:

- "And it could also be part of social responsibility for the companies to use sponsorships for these big non-profit organizations".

- "... being involved by means of putting some money to the sport so that the sport can grow ..."

- "A sponsorship is funding from an elite and established company ..."

- "Sponsorship is by all means coming from supporting stakeholders, to support the course thereof. It is done by either by offering free goods and/or services ..."

Theme 3: Attitudes towards the sponsors of the Springboks. The Primary objective of the study was to explore the attitudes sports consumers have towards team sponsors as a result of the sponsorship partnership. The categories identified in Table 3 that describe the attitudes of consumes towards the sponsors of the Springboks are discussed below.

Category 1: Positive attitude towards the sponsors. From the focus groups and the naïve sketches, it was found that most of the participants had a positive attitude towards the sponsors. They felt that the sponsorship agreements built positive relations, that they promoted the sport, endorsed team worth and promoted a sense of unity and nation building. Some participants mentioned that they felt as though the sponsors were more strategic and their sponsorship was more of an act of corporate social responsibility. Lastly, a few participants' attitudes towards the sponsors were positive as they felt that the sponsor brands were well known already and, therefore, their attitude was not as a result of the sponsorship itself. The following quotes were extracted from the focus groups, as well as the naïve sketches to validate the findings: 
- “... sponsors are doing a great job in providing financial support to our Springbok team, so that they can excel in their game ..."

- "I feel it is great that they support the national team by providing a means, but it does not mean that I consider these brands to be my favorite".

- "Positive ... they endorse teamwork, sports, healthy lifestyle, nation building ..."

- “... I am thinking of how proud South Africans were to host the world cup or when the Springboks won the World Cup. It brings people together; it fosters a sense of unity ..."

- "Neutral, there are a lot of sponsors and their decision to sponsor the Springboks does not influence my feelings ... Most of these companies also sponsor other areas if development within the country".

- "... I look up to these companies for providing support for our national team ..."

- “... positive, as it demonstrates support and appreciation for the game of rugby ..."

- "I think they are good, they have presence, but they could do a lot more ..."

- "Indifferent, however, there is a certain level of appreciation, as they are national team sponsors".

- "Good sponsors"

- "... fosters unity ..."

\section{Strategies employed to ensure data quality}

Klenke (2008, p. 38) states that quality assurance of data in qualitative research can be described through strategies such as credibility, transferability, dependability and confirmability. In this study, credibility in this study was attained by prolonging the engagement with the participants and also building trust. This was done by honouring the views and opinions of the participants, ensuring that the participants are in an environment that encourages openness and honesty. The inclusion criteria that were used in selecting the target population were clearly described. This is done to ensure that future researchers who may wish to replicate the study can have sufficient information regarding the characteristics that the population should possess. Dependability was ensured by the recoding procedure. Since two focus groups were used to collect primary data from the participants, the data were supported by naïve sketches completed by the participants, as well as recorded on an audio recorder (Jooste et al., 2013, p. 4).

\section{Discussion}

the focus group discussion, as well as in the naïve sketches, it was found that the attitude of the participants in this study was generally positive towards the sponsors of the Springboks. The participants believed that the sponsorship built positive relations, that the companies promoted the sport, endorsed team worth and promoted a sense of unity and nation building. The participants further mentioned that the sponsors were doing a great job in providing financial support to the Springbok team which facilitated their excellent performance. Some reasons given by the participants for the positive attitude towards the sponsors as a result of the sponsorship are as follows:

- Participants believed that the sponsorship demonstrates support and appreciation that sponsors have towards rugby.

- Participants believed that the sponsorship of the Springboks fosters unity and brings people together within South Africa.

- Participants believed that the sponsors endorsed good qualities such as teamwork, sports, healthy living among people and nation building.

In summary, it was established that the participants had a positive attitude towards the sponsors of the Springboks as a result of the sponsorship agreement. According to Rani (2014, p. 60), consumers generally have specific beliefs and attitudes about products and such beliefs and attitudes make up brand image and affect consumer behavior. It is possible that when consumers have a positive image of the brand, they may consider the brand when seeking brands to fulfil their needs. It is, therefore, important that companies try to change the beliefs and attitudes of consumers in a favorable manner (Rani, 2014, p. 60). It is also important to note that from the focus groups it was evident that some of the participants had a prior positive attitude towards the companies that are Springbok sponsors. The participants mentioned that this was the case because of the existing reputations of the brands and not necessarily because of the sponsorship of the Springboks.

\section{Recommendations and conclusion}

Participants had a positive attitude towards the sponsors of the Springboks. This positive attitude was because participants felt that sponsors were endorsing good values that they perceived to be important, such as teamwork, healthy living and nation building. The responses of the participants or the participants' attitudes were general in nature and were not specific to the sponsors individually. It is recommended that each sponsor uniquely identify the attitude that the consumers have towards their brand as a result of the sponsorship regularly. This can assist sponsorship managers, as well as marketing executives in determining whether sponsorship deals can be renewed at the time of their contractual expiration date. If the sponsorship has not improved consumer attitudes, companies need to, then, re-evaluate their commitment and seek marketing and communication tools that will yield expected results. 


\section{References}

1. Alay, S. (2008), Female consumers' evaluations of the sponsorship and their response to sponsorship, South African Journal for Research in Sport, 30 (2). Available at: http://reference.sabinet.co.za/webx/access/electronic_journals/sport/sport_v30_n2_a2.pdf.

2. Bühler, A. \& Nufer, G. (2010). Relationship marketing in sports. Burlington: Butterworth-Heinemann.

3. Cant, M.C., Van Heerden, C.H. \& Ngambi, H.C. (2010). Marketing management: A South African perspective. Cape Town: Juta.

4. Carmel, L.D. (2015). Rugby: Sponsorship beats TV rights. Available at: http://www.financialmail.co.za/coverstory/2015/01/15/rugby-sponsorship-beats-tv-rights.

5. Carvalho, C.A. (N.D). Impact of consumer attitude in predicting purchasing behavior. Available at: http://www.iaso.com.br/pdf/Impact\%20of\%20Consumer\%20Attitude\%20in\%20Predicting\%20Purchase\%20Beha vior.pdf.

6. Dos Santos, M.A. (2014). Strategies in sport marketing: Technologies and Emerging trends. United States: Business Science Reference. Available at: https://books.google.co.za/books?id=CRCXBQAAQBAJ\&pg=PA240\&dq=definition+ of+sponsorship\&hl=en\&sa=X\&ved=0ahUKEwi-r5mNwuPNAhWBJcAKHQ3wAf0Q6AEIPTAE\#v=onepage\&q= definition\%20of\%20sponsorship\&f=false. Accessed on 2016-07-08.

7. Du Plessis, F.M., Van Heerden, N. \& Cook, G. (2010). Integrated marketing communication. $3^{\text {rd }}$ ed. Pretoria: Van Schaik.

8. Du Plessis, P.J., Rousseau, G.G., Boshoff, C., Ehlers, L., Engelbrecht, M., Joubert, R. \& Sanders, S. (2007). Buyer behavior: Understanding consumer psychology and marketing. $4^{\text {th }}$ ed. Cape Town: Oxford University Press.

9. Ferrand, A., Torrigiani, L. \& Povill, A.C. (2007). Routledge handbook of sports sponsorship: successful strategies. Oxon: Routledge. Available at: https://books.google.co.za/books?id=2CJ9AgAAQBAJ\&pg=PA47\&dq=definition+of+ sponsorship\&hl=en\&sa=X\&ved=0ahUKEwicmq_Qw-PNAhVFKcAKHaLyDiEQ6AEISzAH\#v=onepage\&q= definition\%20of\%20sponsorship\&f=false. Accessed on 2016-07-08.

10. Jalleh, G., Donovan, R.J., Giles-Corti, B. \& Holman, C.D. (2002). Sponsorship: impact on brand awareness and brand attitudes, Social Marketing Quarterly, pp. 35-45. Available at: http://smq.sagepub.com/content/8/1/35.full.pdf+html.

11. Kardes, F.R., Cline, T.W. \& Cronley, M.L. (2011). Consumer behavior: Science and practice. South-Western: Cengage Learning.

12. Kickoff. (2015). SAFA announce Burger King Sponsorship worth R25 million. Available: http://www.kickoff.com/news/59197/safa-announce-burger-king-sponsorship-worth-r25-million.

13. Kim, Y.K., Ko, Y.K. \& James, J. (2011). The impact of relationship quality on attitude toward a sponsor, Journal of Business \& Industrial Marketing, 26 (8), pp. 566-576. Available at: http://dx.doi.org/10.1108/08858621111179840.

14. Malhotra, N.K., Birks, D.F. \& Wills, P. (2012). Marketing research: An applied approach. $4^{\text {th }}$ ed. Harlow: Prentice Hall.

15. Mason, K. (2005). How corporate sport sponsorship impacts consumer behavior, The Journal of American Academy of Business, Cambridge, 7 (1), pp. 32-35.

16. Nevill, G. (2014). Weighing in on sponsorship. Available at: http://themediaonline.co.za/2014/04/weighing-in-onsports-sponsorship/.

17. News 24. (2013). Spar renews netball sponsorship worth R20 million. Available at: http://www.news24.com/Archives/City-Press/Spar-renews-netball-sponsorship-worth-R20-million-20150429.

18. Nixon, A. \& Wild, D. (2010). Assessing and demonstrating data saturation in qualitative inquiry supporting patient-reported outcomes research, Expert Review of Pharmacoeconomics \& Outcomes Research, 10 (3), p 269281. Available at: http://www.tandfonline.com/doi/full/10.1586/erp.10.30.

19. Pedroncelli, P. (2016). Cricket SA announces new Standard Bank Sponsorship. Available: http://afkinsider.com/125991/cricket-sa-announces-massive-standard-bank-sponsorship/.

20. Rani, P. (2014). Factors influencing consumer behavior, International Journal of Current Research and Academic Review, 2 (9), pp. 52-61. Available at: http://www.ijcrar.com/vol-2-9/Pinki\%20Rani.pdf.

21. Repucom. (2012). Consumer and television audience analysis rugby. 8 August.

22. Rugby Football History. (2007). The history of South African rugby. Available at: http://www.rugbyfootballhistory.com/south_africa.html.

23. Shank, M.D. (2009). Sports marketing: A strategic perspective. $4^{\text {th }}$ ed. Upper Saddle River: Pearson International.

24. Sport24. (2015). Boks lose second sponsor in as many days. Available at: http://www.sport24.co.za/Rugby/bokslose-second-sponsor-in-as-many-days-20151123.

25. Springbok Supporter. (2011). History of the Springbokke. Available at: http://www.springboksupporter.co.za/SARU/History.aspx.

26. Smith, A., Graetz, B. \& Westerbeek, H. (2008). Sports sponsorship, team support and purchase intentions, Journal of Marketing Communications, $14 \quad$ (5), pp. 387-404. Available at: http://www.aaronctsmith.com/Article\%20PDFs/Smith\%20JMC.pdf.

27. Styan, J. (2012). BMW gives Springboks new cars. Available at: http://www.fin24.com/Companies/Advertising/BMW-gives-Springboks-new-cars-20120719.

28. Telegraph Media. (2008). A short history of the Springboks. Available at: http://www.telegraph.co.uk/news/3269349/A-short-history-of-the-Springboks.html. 
Problems and Perspectives in Management, Volume 14, Issue 3, 2016

29. Woodside, F.M., Summers, J. \& Johnson-Morgan, M. (2008). Sponsorship leveraging improves consumer attitudes and purchase intentions towards the sponsoring brand - but is it relevant for FMCG packaging? Available at: https://eprints.usq.edu.au/3763/3/Woodside_Summers_JohnsonMorgan_ANZMAC2007_PV.pdf.

30. Zhang, Y. \& Wildemuth, B.M. (N.D.). Qualitative analysis of content. Available at: https://www.ischool.utexas.edu/ yanz/Content_analysis.pdf. 